\title{
INFECÇÃO POR HPV E PATOLOGIAS ASSOCIADAS: INCIDÊNCIA E TRATAMENTO EM UMA INSTITUIÇÃO DE SAÚDE
}

\author{
Maria Cristina Alves MOREIRA ${ }^{\mathbf{1}}$ Francisca Marina de Souza FREIRE²
}

${ }^{1}$ Licenciatura em Biologia/Universidade Estadual Vale do Acaraú (UVA); Especialista em Saúde Pública/Universidade Aberta Vida (UNAVIDA), Brasil. E-mail: cristinamoreira58@hotmail.com

${ }^{2}$ Doutora em Psicologia Social/Universidade Federal da Paraíba (UFPB); Graduada em Psicologia/UFPB; Professora Assistente/Centro Universitário de João Pessoa (UNIPÊ), Brasil. E-mail: marinasfreire@ hotmail.com

Introdução: Dentre as doenças relacionadas às sexualmente transmissíveis, destaca-se o HPV (Papiloma Vírus Humano), devido ao grande número de casos registrados. Este vírus atinge grande parte da população sexualmente ativa, acometendo principalmente os órgãos genitais. O Brasil lidera mundialmente em incidência de HPV, e as principais vítimas são as mulheres, causando o câncer de colo do útero, apresentando-se sob três fases, antes de atingir o estágio invasor, quando se torna mais difícil a cura. Este estudo objetivou verificar a frequência de mulheres atendidas no CDC (Centro de Diagnóstico do Câncer), em João Pessoa/PB infectados pelo vírus HPV ou por patologias associadas. Metodologia: Tratou-se de um estudo descritivo exploratório quantitativo, no CDC, instituição de referência para o diagnóstico e tratamento destas doenças. Foi utilizado o método de pesquisa ativa, por meio da consulta aos livros de registro da instituição, referentes aos atendimentos realizados entre janeiro de 2009 a março de 2010. Os dados foram analisados por meio do programa estatístico SPSS.15, realizando-se estatísticas descritivas. Resultados e Discussão: Foram atendidas 804 mulheres provenientes das quatro regiões geográficas do Estado da Paraíba. A faixa etária variou de 15 a 84 anos, com maior frequência de 25 a 34 anos (32\%), seguida de 15 a 24 anos (25\%). Foi observado uma frequência significativa de neoplasias em alto grau, como a NIC III, principalmente em mulheres abaixo dos 45 anos. A região com maior frequência nos diagnósticos foi o Agreste paraibano $(\mathrm{f}=301)$. Foram realizados 5955 procedimentos no combate ao câncer uterino. Destaque para o número de colposcopias realizadas $(f=2468)$, em virtude do elevado índice de neoplasias de alto grau. Conclusões: Ressalta-se a importância do combate ao câncer uterino para a saúde da mulher, haja vista o alto índice de infecção. Reforça-se a necessidade de revisão de estratégias de atuação, de maneira que as ações educativas promovidas pelas equipes de atenção básica busquem as condições e informações necessárias para a prevenção do colo uterino, como também promovam a conscientização para a prevenção do contágio.

Palavras-chave: Centro de Diagnóstico do Câncer; DSTs; Promoção de saúde. 